\title{
Actos anticipados de campaña presidencial y efectos en la opinión pública: El caso de Rafael Moreno Valle en Puebla
}

\author{
Anticipated acts of the presidential campaign and effects on public \\ opinion: The case of Rafael Moreno Valle in Puebla
}

Rosa María HERMIDA QUEZADA

Benemérita Universidad Autónoma de Puebla (México)

Recibido: 13 de junio del 2017 Aceptado: 07 de septiembre 2017

\begin{abstract}
Resumen
Todo mensaje transmitido por líderes políticos, como parte del intercambio de símbolos y representaciones cognitivas que comprende la comunicación política, incide en la opinión pública a través del mensaje. El discurso político se ha estudiado en distintas dimensiones, pero existe una delgada línea entre los mensajes de la campaña permanente, parte de la comunicación gubernamental y los mensajes persuasivos dentro de la comunicación electoral. En México, aunque esto ha sido tan recurrente, se ha examinado ocasionalmente a pesar de que mediante diferentes mecanismos es posible profundizar en el análisis del mensaje, argumentar con mayor solidez su objetivo y ponderar los efectos que inciden en la opinión pública. El presente trabajo reporta un estudio de caso sobre presuntos actos anticipados de precampaña por un servidor público en funciones expuestos y busca confirmar, a través de una metodología cualitativa, que el discurso político de un servidor público durante actos anticipados de campaña constituye una violación a la ley e incide en la opinión pública.
\end{abstract}

\section{Abstract}

Any message transmitted by political leaders, as part of symbols exchange and cognitive representations that comprehend political communication, affects public opinion through the message. The discourse has been studied in different dimensions, however there is a fine line between the messages of the permanent campaign, part of the government 
communication and the persuasive messages within the electoral communication In Mexico, this is as recurrent as occasionally examined. The mechanisms that regulate these practices could deepen the analysis of the message to argue with greater strength about its objective, considering the effects that affect public opinion. This essay analyzes a case study that raises alleged anticipated acts of pre-campaign by a public servant and seeks to confirm, through a qualitative methodology, that political discourse of a public servant during early campaign events is a law violation and affects public opinion.

Palabras clave: Campaña política, legislación electoral, comunicación política, discurso político y opinión pública

Keywords: Political Campaign, Electoral legislation, Political Communication, Political Discourse, Public Opinion

\section{Introducción}

El mensaje en el discurso político se analiza desde la carga de significados, su construcción, el canal en el que se transmite, o la manera en que llega a ser interpretado desde la realidad social del votante. De hecho, la preocupación por profesionalizar la creación y transmisión de mensajes bien dirigidos en los discursos políticos ha empujado a que expertos en marketing, publicidad y comunicólogos como profesionales dentro del ámbito político, induzcan a líderes políticos a invertir grandes cantidades de su presupuesto en campañas electorales para persuadir a votantes a integrarse en las filas de su ideologia. De hecho, estudios a propósito de la profesionalización de las campañas en México, afirman que gracias a la apertura del sistema electoral, las campañas electorales presidenciales del 2000 tuvieron francas posibilidades de real competencia (Sánchez et al, 2018), de hecho, su resultado debe ser analizado contemplando los cambios en tácticas y estrategias de campaña de los partidos de oposición (Domínguez en Díaz, 2015).

Tomando en cuenta esto, se comprende una de las formas en profundizar el análisis del discurso político es contextualizando la realidad social, en otras palabras, desde un sitio lleno de experiencias propias o pseudoentornos donde el individuo crece y se forja en valores (Steel, 2003), donde la cultura forma parte del comportamiento electoral a partir de la 
necesidad de una identidad social, donde los símbolos evocan emociones dentro del imaginario colectivo, se habita e interpreta (Peschard, 2000); o desde la personalidad de los líderes políticos que, tratado como marca comercial, ha evolucionado a la personalización del candidato al construir su imagen como una persona cuyos atributos individuales representan a un partido o ideología (Mazzoleni, 2010); o bien desde la coexistencia de la relación simbiótica entre dominio y poder, utilizada para crear lazos simbólicos con la sociedad a partir de discursos que expresan, la relación del poder, su abuso, cómo se produce desde grupos e instituciones dominantes y es transmitido a la sociedad, creando y manteniendo desigualdad social (Van Dijk, 2004). Sin duda, la forma en que los medios toman posturas ideológicas o comercialistas infieren en el análisis de su captación como de la re-transmisión del mensaje. En este sentido, el comercialismo en los medios informativos al evitar la cobertura profunda y reflexiva y tender al infoentretenimiento (Echeverría, 2018), incide de manera directa en la opinión pública, quien funge como contrapeso al ejercicio de poder, pues toma directamente la decisión de apoyar o sancionar al líder o partido político en las urnas, arropando, contradiciendo o polarizando ideologías políticas, después de todo «[...] la opinión pública, en cuanto opinión en público, influye en la opinión del público» (Ceri en Mazzoleni, 2010).

Estas afectaciones son el objeto de estudio del presente ensayo. Si bien autores como Gianpietro Mazzoleni o Noelle-Neumann, entre otros, han estudiado y desarrollado teorías de posibles afectaciones por la sobre exposición de propaganda electoral en los votantes, también es cierto que la opinión pública de acuerdo con Habermas es un espacio ciudadano (Morales y Gómez et al, 2011) dentro del cual se integran realidades individuales que convergen en una realidad social contextualizada en tiempo y espacio vinculado a la dinámica del poder (Mendoza, 2011). La resolución SER-PSC-43/2017 presenta presuntos actos anticipados de campaña ocurridos en febrero de 2016 por Rafael Moreno Valle, Gobernador Constitucional del Estado de Puebla que consisten en la difusión de propaganda de la edición especial de la revista Líderes Mexicanos con una entrevista realizada al 
Gobernador de Puebla, utilizando su imagen personal en la portada con la leyenda "Rafael Moreno Valle. El nuevo presidenciable", exponiendo en la entrevista logros y avances de su gobierno como gancho publicitario. Esta difusión se realizó en spots de radio, televisión y diarios de circulación nacional; también difundieron publicidad impresa colocadas en parabuses y espectaculares en distintos puntos de la República, así como estaciones de metro y metrobus de la Ciudad de México.

\section{Metodología de investigación}

La propuesta metodológica de enfoque cualitativo para el análisis del presente estudio, se auxilia con tres estrategias que se desarrollan en momentos escalonados. Con base en una indagación exploratoria, se ha encontrado que el conjunto de evidencias anexas a la resolución consiste en un paquete de spots de radio y televisión en versión estenográfica con capturas de imágenes referenciadas para su archivo. Existe también captura del material expuesto físicamente de la publicidad impresa. La entrevista en versión impresa en la revista, incluye también una captura de imágenes para referencia, y una parte de esta se referencia en la página web de la misma revista. Al ser retiradas de todo sitio público, sólo se existen en esta versión. Debido a las evidencias disponibles, se ha decidido realizar el presente estudio de caso en tres fases utilizando en conjunto un diseño evaluativo con la finalidad de obtener de manera sistemática y rigurosa, efectividad y validez en los resultados. En la primera, se ha desarrollado en el presente documento teoría fundamentada, con la finalidad de explicar la relación entre el mensaje del discurso político y la opinión pública, incluyendo postulados de imaginario social, cultura política y opinión pública alrededor del corpus actual; en la segunda, a partir de una técnica de análisis estructural, se propone manejar la entrevista en versión estenográfica como corpus, en búsqueda de tendencias discursivas a partir de la definición de la realidad de la entrevista emitida por el servidor público desde el análisis de contenido; la tercera, también bajo técnica estructural, consiste en analizar con mayor profundidad la entrevista en versión estenográfica del servidor público, de tal forma que con 
el análisis crítico del discurso se obtengan hallazgos que expliquen su forma sintáctica y retórica.

La decisión inicial de tomar la entrevista como punto de partida para su análisis radica en que existe una emisión directa del discurso del servidor público. Cabe en este punto referenciar que, "la entrevista política es un género del periodismo informativo que refleja las respuestas de un responsable público, cuyas opiniones, debido al cargo que ostenta o a la actualidad informativa, son de interés general" (Yanes, 2006). La entrevista disponible actualmente resulta un corpus de alcance limitado, y debido a esto, se ha tomado la decisión de incluir en la población material categorizado como comunicación gubernamental que haya incurrido en violaciones de actos anticipados de precampaña durante su periodo de gobierno, con la finalidad de ampliar el alcance de los hallazgos y confirmar la calidad del discurso del servidor público.

\section{Resultados de investigación}

\section{Fase I - Teoría fundamentada}

La postulación de esta primera fase se sustenta en el diseño de teoría fundamentada. En este sentido, partir de la hipótesis H2 existen discursos de servidores públicos que resultan propaganda electoral, se ha desarrollado esta tesis a partir de teorías de comunicación política y opinión pública, con énfasis el tratamiento del mensaje desde el discurso simbólico, para confirmarla o rechazarla. Aunque la validación final se complementa con las otras dos fases del estudio, durante esta primera fase se contextualizó el estudio de caso dentro del imaginario social mexicano con la teoría de la opinión pública de Jürgen Habermas, permitiendo contrastar el comportamiento racional de un actor político y uno manipulador. Por otro lado, la teoría de la espiral del silencio por Noelle-Neumann, se utilizó como integradora del contexto del imaginario social, el estado de la cultura política y las posibles afectaciones a la opinión pública, lo que permitió la exhibición de tendencias de 
comportamiento de actores políticos, medios, así como posibles incidencias en la opinión pública.

Los hallazgos de esta primera fase, arrojan en primer lugar que el comportamiento del actor político no se rige por el "buen actuar", sino que, al exponer abiertamente su ambición por alcanzar la candidatura presidencial, el servidor público sobrepasa la recurrencia de violaciones electorales, distanciándose paulatinamente de la comunidad, alianzas públicas y medios, hasta seleccionar a unos cuantos por beneficios comerciales. En segundo lugar, basado en la literatura, el discurso utilizado en su campaña estuvo fuertemente cargado de significados y creó lazos con la ciudadanía, debido a esto y por ser el primer gobierno de alternancia, se tenían grandes expectativas respecto a su conducir durante su gestión. Sin embargo, desde su primer año de gobierno su discurso se modificó con miras a la aspiración presidencial, tornándose informativo respecto a su estado de resultados con un fuerte manejo de imagen personal, dejando de escuchar las necesidades reales de la región y en consecuencia, alejándose del concepto de democracia que define el modelo habermasiano.

La exposición de sus violaciones electorales a nivel nacional y lo que se convirtió en una abierta lucha con el INE, quien reguló en más de una ocasión su comportamiento, dio pie a que los medios, como intermediarios e interpretadores del mensaje, lo enmarcan como un personaje conducido fuera de la ley, lo cual contrasta con la postulación de Noelle-Neumann al mostrar que su gobierno no necesitó ser regulado por la opinión pública, al menos regional. Confirmando así la $\mathbf{H 1}$.

\section{Fase II - Análisis de contenido}

El estudio de caso expuesto en líneas anterior es un fenómeno contemporáneo que parte de una estrategia metodológica de enfoque cualitativo (Cea, 1996). Al categorizar las respuestas de la entrevista como unidades de análisis, se obtendrán inferencias de manera objetiva y sistemática para definir la dimensión específica del mensaje. En otras palabras, esto ayudará a conceptualizar la realidad de la entrevista. Debido a esto, la herramienta 
metodológica bajo la cual será examinada la entrevista será el análisis de contenido (Acosta, 2013).

\section{Diseño de la investigación}

Debido a que la entrevista cuyo discurso es emitido directamente del servidor público es una de las evidencias documentales actualmente disponible, se toma en cuenta que, "para el análisis de contenido de mensajes difíciles de encontrar, como documentos históricos, la población puede definirse por la accesibilidad de los materiales." (Neuendorf, 2017). Aunque forma parte de un proyecto más robusto, y en función de los objetivos de la investigación, esta fase mantiene diseño explicativo debido a que se pretende valorar el comportamiento de un servidor público en función de su discurso político. De tal forma que la entrevista, recolectada en su versión impresa, se procesa y analiza contemplando como contexto la cultura política en 2016, año en que fue publicada, pues al reconocer sus rasgos importantes y sus características se definirá la tendencia gubernamental o electoral del mensaje, por tanto, su alcance es descriptivo (Cea, 1996), pues:

"Busca especificar propiedades, características y rasgos importantes de cualquier fenómeno que se analice. Describe tendencias de un grupo o población, Es decir, únicamente pretenden medir o recoger información de manera independiente o conjunta sobre los conceptos o las variables a las que se refieren." (Hernández, et al., 2010)

\section{Diseño muestral y libro de códigos}

Tomando en consideración que el discurso político del servidor público en la entrevista es comunicación política, se han definido dos dimensiones para definir la naturaleza del mensaje: comunicación gubernamental y comunicación electoral.

La entrevista en versión impresa es el insumo principal de la investigación dentro de la cual se mide la repetición de conceptos expresados en las respuestas del entrevistado. Para explicarlos y relacionarlos con las teorías fundamentales, se toma 
la entrevista, dentro del conjunto de evidencias anexas en la resolución SER-PSC43/2017, y debido a la poca cantidad de respuestas, no es necesario extraer una muestra representativa, debido a que "con una población pequeña, puede que no sea necesario extraer una muestra más pequeña y representativa de la población. Más bien, todos los casos en la población pueden incluirse en el estudio, que luego se llamaría censo" (Neuendorf, 2017).

Una vez concentrados y sistematizados los datos, a través de una serie de codificaciones se busca no sólo agruparlos sino compararlos con el esquema emergente para fundamentarlo (Hernández et al, 2006), de tal forma que de una entrevista, con población de 24 respuestas censadas, donde la respuesta es la unidad de análisis, se obtiene seguridad al 100\% del parámetro de tendencia del discurso político.

En este sentido, el procesamiento de la información se transforma debido a su sistematización y de categorización en datos lo que da oportunidad de complementar con otros hallazgos. (Acosta, 2013). La propuesta de operacionalización se encuentra en el Anexo 1 de este documento.

\section{El discurso en la Opinión Pública y Jurgüen Habermas}

Si bien la postura de Habermas respecto a la opinión pública y el discurso es ideal, su referencia en este estudio funge como rector de comportamiento ideal para el funcionamiento de una democracia representativa, donde la construcción del significado cultural y Estado se relacionan (Castells, 2008). Para efectos del presente estudio, se describen los conceptos que auxilian a la comprensión del estudio de caso.

Para Habermas, la opinión pública es un proceso racional, donde el ciudadano es consciente y responsable de actuar y participar con raciocinio en pro de un bien común. Tal como 
Peschard señala respecto al enfoque racional en su estudio respecto a la conducta electoral (2010).

El discurso se lleva a cabo por objetivos normativos pero a través de un lenguaje simbólico hacia la población, con la finalidad de crear lazos entre ellos. Aunque acepta que la información que se transmite llega en forma desigual, para él los procesos comunicativos resultan primordiales tanto para la opinión pública como para las condiciones en las que se da en el espacio público, en el que se habla de cualquier tema pues no existe regulación formal, sin embargo, su condición es mantener neutralidad, y asumiendo que el concepto de justo se adquiere con los valores durante la primera infancia, las condiciones de igualdad así como lo bueno dentro de la comunidad, son logrados (Habermas, 1992). Toma también en cuenta que el mensaje no es tratado sólo por los actores políticos y la sociedad, sino que da lugar a los medios como canal o intermediario del proceso de comunicación (Habermas en Betancourt, 2014). Aunado a esto, refiere a la manipulación como herramienta utilizada por el poder para influir en los ciudadanos deformando en consecuencia a la opinión pública siendo ésta el eje de cohesión social y legitimación (Habermas en Sopena, 2008). De hecho, ve a la esfera pública moderna como una forma manipuladora de publicidad, donde políticos y expertos en comunicación, manipulan un público falso (Habermas en Constantisnescu, 2012) Para Habermas, la interacción discursiva es sinónimo del debate público, principalmente en condiciones de deliberación o actividad comunicativa. Para esto, en su tratado, Ética del discurso, describe postulados normativos con las cuales se toman decisiones y se forma una opinión pública racional, estos son: apertura, argumentos razonados, el bien común de la comunidad política, honestidad en los argumentos, apertura hacia un consenso racional aunque se llegue por principio de mayoría; todo esto para obtener no sólo amplitud en el debate, sino en conjunto, el sentido democrático (Habermas en Betancourt, 2014).

El objeto del debate versa en la actuación administrativa y política de los gobernantes, dicho de otra forma, la opinión pública tiene como función criticar y vigilar el dominio estatal en 
debates, o en épocas de elecciones para ganar igualdad civil y política, como parte de los ideales democráticos (Habermas en Mendoza, 2011). En otras palabras, hace de crítica y control (Habermas en Sopena, 2008)

El hecho que de conciba a la esfera pública como un espacio simbólico donde se efectúa la congregación racionante de las personas (Habermas en Fraser, 1999; Dijkman, 2012), permite su adaptabilidad para los espacios digitales actuales. Tanto que llegó no sólo a aceptar la importancia del papel de los medios en la comunicación, sino a reescribir sus teorías ampliando la esfera pública al uso de plataformas digitales (Habermas en Constantisnescu, 2012).

\section{Contexto sociopolítico en México}

México, un país cuyo sistema hegemónico inició su etapa formativa en 1946 (Valdés, 2019), inicia su transición democrática a finales de los ochenta, dando apertura a elecciones competidas, cuya ciudadanía volcada a la pluralidad se reflejó en la primer alternancia en la gubernatura de Baja California en 1989 (Espinosa et al, 2019). Este paso dio lugar a nuevas reformas electorales, que en conjunto con las procesadas desde 1951 y en 1977 abrieron el camino hacia una democracia con mayor equidad, profesionalismo e imparcialidad reflejado en el pluralismo de la elección de 1994, con incremento significativo en la competitividad en la alternancia federal en el 2000, donde las elecciones presidenciales del 2006 llegaron ser las de mayor pluralismo del siglo (Valdés, 2019). En pocas palabras, el país ha sido testigo histórico del "reformismo electoral" (Valdés, 2000).

\subsection{Realidad social y cultura política en México}

Si bien a través de distintos lentes se ha logrado comprender el papel que la cultura y la política guardan dentro de la sociedad, la carga de imaginarios y realidades transmitidas a la 
colectividad, percibidos como esquemas sociales construidos y evolucionados dentro de la misma en el tiempo, encuentran no sólo validez sino institucionalización y legitimación gracias a su carga simbólica y emocional.

Mientras que en otros tiempos, el símbolo, la imaginación y lo imaginario eran rechazados como fuente de conocimiento científicamente plausible (2012, Cegarra), los imaginarios sociales modernos se distinguen por su capacidad de configurar los sentidos en discursos que determinan historias oficiales, sobre las que se asientan las naciones (Andersen en Quintanilla, 1993). El imaginario da sentido a la realidad socialmente compartida pero en términos antropológicos, es decir, desde lo esencialmente humano pues funciona como el conjunto de imágenes interrelacionadas que constituyen el pensamiento social y colectivo (Durand en Cegarra, 2012). En este sentido, la situación en la que vivimos podemos metaforizarla en tres niveles: económico, político y cultural, antecediendo que el económico y político ejercen discursos dominantes mientras que el cultural lo define como "el nivel del conocimiento y de los imaginarios sociales" que organizan y regulan nuestra vida cotidiana (Pintos, 1995)

El lenguaje, además de construir representaciones simbólicas que aparentemente dominan la realidad diaria, construyen símbolos a partir de la experiencia cotidiana, los recupera y presenta como reales y objetivos. (Berger y Luckman, 2003). Las palabras equivalen a símbolos y por eso hacen de función política específica, en otra palabras, el poder político de la metáfora, a partir del lenguaje simbólico, cumple con funciones cognitivas, de identificación, valorativas, de adhesión o aversión, de pasividad o exaltación y afectivas. De hecho, como poder político, puede utilizarse como "poder para crear realidades" incluso manipulables (Edelman en Aquiles y López, 2011).

La cultura da identidad a una comunidad social a partir de sus símbolos, valores y creencias (Peschard, 2000). La cultura nacional y la lógica del poder y el Estado, han tenido alcance en las distintas clases del país, quien ha heredado respuestas revolucionarias de consensos y 
negociaciones entre caudillos y las fuerzas campesinas. Con el tiempo, la cultura oligárgica en conjunto con las de tipo popular, obrero y campesino, obedecieron a la lucha de masas por el poder que vencieron en distintas ocasiones a la vieja oligarquía entre engaños y mediaciones, a través de la transmisión cultural de símbolos de represión y concesión, negociación y convenio (González, 1981).

Dentro de la evolución histórica, cultural y política a la que se ha sometido el país, se han suscitado cambios drásticos respecto a la institucionalización de comportamientos formales e informales (Lechner, 2013). En otras palabras, el uso de los sistemas de significación ha fungido como herramienta clave para prevalecer la lógica de poder desde tiempos revolucionarios (González, 1981). Sin embargo, el carecimiento de códigos interpretativos en los que se apoya la comunicación política para estructurar y ordenar la nueva realidad se torna indispensable debido a las distintas etapas de polarización político-ideológica que ha tenido el país durante su historia (Lechner, 2013).

Dentro de todo, la cultura política mexicana es el conjunto de la cultura del poder, ideología y tolerancia formal, donde se funden las viejas y nuevas estructuras de marginación y manipulación de la información. (González, 1981)

\subsection{El mensaje en discurso político}

La lógica de poder desde la heredada realidad social revolucionaria, prevaleció a partir del lenguaje (Lechner, 2013)

Siendo que "el voto es el acto político más importante en las sociedades democráticas" (Peschard, 2000), cabe resaltar que durante la etapa electoral, el actor político y los partidos políticos transmiten mensajes direccionados a los votantes. Dicho de otra forma, el lenguaje político persuade teniendo por indicador directo al voto. (López y Chihu, 2001). 
El discurso, bajo estas líneas, es la "construcción de carácter persuasivo que permite comunicar ideas y propuestas, referidas a objetos públicos y/o políticos, tanto a través de palabras como de imágenes, por lo que se dice explícitamente y también por lo que se sugiere" (García et al. en Ahuactzin y Meyer, 2017).

Silvia Gutiérrez expone que definir el discurso político resulta complejo debido a que lo político y lo ideológico, dos de sus características principales, aparecen en casi todos los discursos. Sin embargo, existen características formales con las que puede identificarse: a) su objetivo no es convencer sino reconocer, distinguir y confirmar a sus adeptos e interesar a indecisos; b) es estratégico a partir de la definición de sus propósitos; c) mantiene propiedades performativas; d) su base es polémica; e) su argumento es una tesis (Gutiérrez, 2006).

A partir de un vínculo emocional entre objetos y discursos políticos, el mensaje es utilizado como recurso de dominación o contrapoder a partir del simbolismo en la conducta humana (Edelman en López y Chihu, 2001). En este sentido, existe el poder de controlar el discurso y el poder del discurso para controlar las mentes de las personas, es decir, a partir del discurso público se pueden formar las representaciones sociales en texto y contexto, de aquí la importancia de su control para ejercer su dominación (van Dijk, 2004). De hecho, "trabajar sobre el discurso político hoy, es casi siempre como trabajar sobre el discurso "filtrado" (en el sentido de Chomsky) por los medios de comunicación y tener en cuenta por lo tanto su lógica comunicacional" (Gutiérrez, 2006).

La mercadotecnia al especializarse en el campo político, desarrolló el marketing electoral que, en palabras de Newman (1999) es la aplicación de principios y procedimientos de la mercadotecnia a las campañas políticas a través de individuos y organizaciones. Una campaña electoral es "el proceso por medio del cual una organización de campaña (ya sea un partido político, candidato o grupo de interés) busca maximizar su rendimiento electoral" (Farrell en Díaz, 2015). Incluye todos esos esfuerzos organizados (promocionales o 
financieros) para "informar, persuadir y movilizar" al electorado a través de mensajes (Norris en Díaz, 2015).

\subsection{El modelo de comunicación electoral en México}

La finalidad del modelo de comunicación electoral en México es sostener la equidad en la contienda para mejorar el funcionamiento del sistema democrático, así como mantener a una sociedad informada. Debido a que la radio y la televisión en México explotan un bien de dominio público, están obligados a actuar con legalidad y bajo las normas en materia electoral, y el Estado Mexicano es quien regula dicho modelo (Videoteca Jurídica Virtual, 19 de octubre de 2015).

El objetivo del proceso electoral, de acuerdo al artículo 207 de la Ley General de Instituciones y Procedimientos electorales (LGIPE) de 2014, es renovar en determinados lapsos de tiempo a los integrantes de los Poderes, y comprende 4 etapas: preparación de la elección; la jornada electoral; los resultados y declaraciones de validez y dictamen; y declaraciones de validez de la elección (Sánchez, Meixueiro y Contreras, 2018).

En la reforma electoral del 2014, se incluyeron disposiciones en materia de derecho administrativo sancionador, creando la Sala Regional Especializada, un órgano regulatorio de los procesos electorales, de manera ordenada y expedita. De acuerdo a la Ley Orgánica del Poder Judicial de la Federación, la Sala Regional Especializada conoce y resuelve procedimientos especiales sancionadores previstos en la LGIPE.

El Procedimiento Especial Sancionador (PES), es un mecanismo que por una parte verifica las infracciones a los artículos 41, base III y 134, párrafos VII y VIII de la Constitución Política de los Estados Unidos Mexicanos y regular; mientras que por otra, salvaguardar derechos fundamentales. Gracias a este órgano jurisdiccional existen lineamientos formales para el manejo y transmisión de mensajes, así como amparo y regulación de los mismos, entre otros varios criterios, libertad de expresión de los periodistas y medios de comunicación, figuras públicas y asuntos de interés general como los referidos a propaganda electoral, de tal forma 
que la actuación de un político, representante o candidato de partido; funcionario público; figura pública o; medio de comunicación, casa editorial o periodista, deben regirse y limitarse en sus expresiones públicas a partir de criterios razonados con la finalidad de informar a la ciudadanía con responsabilidad respecto a los asuntos de interés público (Pizaña y Pérez, 2019).

EI TEPJF señala que la primera etapa del proceso electoral es el momento más agudo debido a la relación comunicativa existente entre organizaciones de partidos y ciudadanos. (Videoteca Jurídica Virtual, 19 de octubre de 2015). Respecto a lo anterior, Kaid y Johnson en Sánchez et al. (2018) afirman que en la actualidad, la publicidad política televisada en México es el medio de comunicación dominante entre candidatos, votantes y las elecciones presidenciales en los concursos estatales.

Dicho de otra forma, conocer el PES lleva a profesionales del marketing y comunicación electoral a cumplir al margen de la ley las actuaciones en precampaña y campaña así como considerar el contenido de sus mensajes.

\subsection{Trasfondo electoral en Puebla}

En el estado de Puebla por su parte, la hegemonía del PRI y el pluralismo podrían concluirse como reflejo no sólo a nivel regional, sino local. La composición del Congreso del Estado bien podría ser un buen reflejo del sistema de partidos pues expresa correlación de fuerzas políticas, importante para el contenido de las reformas electorales y para decisiones fundamentales como por ejemplo, el nombramiento de la autoridad electoral. El Congreso estatal mantuvo durante muchos años la mayoría calificada de un mismo partido político, de hecho, logró eliminarla en 2002, siendo así el último de los estados en hacerlo. Si bien han existido múltiples y diversas alternancias tanto en el Estado como en su capital en 1995, la federalización de los procesos electorales locales en el país a partir de la reforma federal de 1996, empujó a que las leyes locales fueran congruentes con la federal y por ende, que las decisiones electorales locales fueran recurridas ante el Tribunal Electoral Federal. En este 
sentido, la reforma electoral poblana de 1995, intentó poner al día a la legislación estatal en la materia, confirmando que el control del organismo electoral no era suficiente condición para controlar el resultado de las elecciones. Estos cambios, sumados a las reformas de 2001, fortalecieron los principios rectores que deben guiar a los organismos electorales: legalidad, imparcialidad, objetividad, certeza e independencia, fortalecieron también las instituciones electorales así como equidad en las condiciones de competencia y cuidado del medio ambiente (Reynoso, 2008).

El modelo electoral Español refiere que la neutralidad en los medios públicos de comunicación tiene constante regulación debido a la natural confrontación de los debates. En éste, se busca simplificar e intensificar los mensajes con la finalidad de obtener igualdad entre los competidores al momento de difundir información a la población votante, regulando también el control del gasto al limitar excesos (Videoteca Jurídica Virtual, 19 de octubre de 2015). Esto, en el caso poblano, corresponde al acceso equitativo a los medios de comunicación, regulación de las campañas electorales y organización de debates, la profesionalización de los servicios electorales y la fiscalización de los recursos asignados a cada partido político entre los candidatos señalado en líneas anteriores (Reynoso, 2008). Ambos tratan de hacer efectiva la legalidad e igualdad por un lado, respetando las exigencias de la administración electoral por otro.

Francisco Aceves en su estudio Elecciones, medios y publicidad política en América Latina: los claroscuros de su regulación, enfatiza la aplicación de las legislaciones al proceso electoral en distintos países bajo la réplica del modelo norteamericano, reconociendo notablemente la profesionalización y surgimiento del marketing político durante el siglo XX (2009), en este sentido, la esfera pública y la opinión pública dirigen las decisiones de estos profesionales, como en el caso de Puebla, donde Reynoso (2008) describe cómo a partir de la regulación de encuestas y sondeos de opinión llegaron a profesionalizarse las campañas electorales. 
La continuidad hegemónica estatal ha sido tema de análisis tanto por al conservadurismo social y político en Puebla, como por las cuestionables e ilícitas actuaciones de los últimos gobernantes priístas.

La contienda electoral del 2010 implicó para los candidatos gran esfuerzo para sacar del poder a un partido cuya reputación se encontraba debilitada y fragmentada. Rafael Moreno Valle, contendiente en la alianza Compromiso por Puebla, mostró durante su etapa electoral habilidades comunicativas excepcionales. Tanto su discurso como su personalidad en conjunto con sus atributos profesionales, lograron impactar a gran parte de votantes indecisos y resentidos, obteniendo el triunfo en esa contienda. Sin embargo, desde los primeros años de su gobierno modificó su comportamiento alejándose paulatinamente de la participación ciudadana y rompiendo las alianzas que antes le habían legitimado. Este cambio de comportamiento tanto en la construcción estratégica del mensaje como en sus acciones de gobierno, expusieron a un servidor público preocupado cada vez más por su imagen pública mostrando desde su primer año en funciones, ambiciones federales (Meyer, Castillo y Rios, 2013).

\section{Estudio de Caso: Rafael Moreno Valle. El nuevo presidenciable}

Este particular periodo de gobierno se vio envuelto por las constantes controversias, no sólo por las decisiones que contradecían sus estados de resultados, principalmente el incremento de inseguridad y endeudamiento estatal, sino por las actuaciones del gobernador respecto a sus recurrentes infracciones en materia electoral de alcance local y federal. A pesar de que las próximas elecciones presidenciales serían llevadas a cabo en 2018, desde su primer informe de labores, en 2011, dedicó buena parte de sus recursos para difundir su estado de resultados evidenciando así su eficiencia como servidor público. Sus repetidas luchas con el Instituto Nacional Electoral tuvieron su ápice cuando en 2016 fue difundida una propaganda a nivel estatal y federal, cuyo slogan era: "Rafael Moreno Valle, el nuevo presidenciable", 
resultando cuestionados él por presunta infracción electoral, personas morales por presunto apoyo y la coalición Compromiso por Puebla a la que representaba.

Debido a lo anterior, se expone la importancia que las afectaciones de dicho comportamiento llegó a tener sobre la opinión pública. Si bien las regulaciones electorales establecen tiempos y techos financieros específicos para la propaganda electoral en tiempos de precampaña y campaña en pro de mantener firmes los principios de la democracia, resulta de importancia analizar a profundidad las teorías de afectación a la opinión pública dentro las limitaciones que como servidor público debe mantener la figura de un gobernador.

\subsection{La reclamación}

El estudio de caso, de la reclamación expuesta en la resolución SER-PSC-43/2017 sobre presuntos actos anticipados de precampaña, cuestiona, para efectos del presente estudio, las posibles afectaciones a la opinión pública resultado de la difusión de propaganda en distintos puntos la República Mexicana.

La denuncia es interpuesta por el Partido de la Revolución Democrática y el Partido Revolucionario Institucional, Rubén Moreno Cosmes, Luis Alberto Aguilar Sumano, José Manuel Restrepo Menéndez y Fermín Salas Álvarez y Patricia Esperanza Díaz Guzmán de manera conjunta, los últimos por derecho constitucional; y corre en contra Rafael Moreno Valle Rosas, Gobernador constitucional del Estado de Puebla, el Partido Acción Nacional y la Revista Líderes Mexicanos en un inicio, pues durante la indagatoria y verificación de datos, se anexaron al Secretario de Gobierno del estado de Puebla, al Coordinador General de Comunicación, Difusión y Promoción del Gobierno del estado de Puebla y a 82 empresas que fueron quienes difundieron la publicidad de la Revista Líderes Mexicanos. La queja suscribe que la entrevista que la revista Líderes Mexicanos realizó y publicó en su revista al entonces gobernador de Puebla en su edición del 27 de septiembre de 2016, bajo el título "Resultados que se notan: Rafael Moreno Valle Rosas", en la que exponen balance y resultados de su gestión y ha fungido como gancho publicitario no sólo para portada de la 
revista, utilizando la imagen del servidor público como portada, se convirtió en herramienta propagandística difundida en físico y en la página de internet, así como en exhibidores de publicidad del metro, metrobus y tren ligero de la Ciudad de México, así como en espectaculares, parabuses, radio y televisión abierta a nivel nacional bajo la leyenda "Rafael Moreno Valle, el nuevo presidenciable".

Aunque la reclamación se centra en cuatro puntos: promoción personalizada de servidor público; uso indebido de recursos públicos; actos anticipados de precampaña y campaña; difusión de propaganda gubernamental fuera del territorio y; temporalidad permitida por la ley; para efectos del presente estudio se realiza análisis de dos de ellos: promoción personalizada y actos anticipados de campaña. Los hechos tuvieron lugar dentro de la vigencia del Código de Instituciones y Procesos Electorales del Estado de Puebla vigentes en 2013, y de acuerdo a la queja, infringiendo los artículos: Artículo Constitucional 134. Párrafos 7 y 8 de la Constitución Federal; párrafo 1, inciso a); 442, párrafo 1, inciso f), 446, párrafo 1 incisos a) y b); 447, párrafo 1, inciso e); y 449, párrafo 1, inciso d) y f); de la Ley General de Instituciones y Procedimientos Electorales.

\subsection{Principios de representación democrática}

Existen cinco principios establecidos en la reforma constitucional de 1996 que rigen tanto la legislación electoral como el desarrollo de los procesos comiciales, estos son: legalidad, equidad, certeza, objetividad y profesionalismo. La actuación bajo estos principios es obligatorio para todas las leyes electorales de México así como autoridades en la materia, sin embargo, cada congreso tiene la facultad de crear o reformar normas que conduzcan mejor hacia estas actuaciones. Debido a esto, la Suprema Corte de Justicia dictamina la constitucionalidad de las leyes y actos de las autoridades electorales (Valdés, 2000).

Conducirse bajo estos principios mantiene en congruencia el proceso electoral, dando cauce y sentido al régimen democrático.

\subsection{Principios y límites de actores políticos en materia electoral}




\section{Obligaciones de los actores}

Dentro de estas normas que se condicionan durante las contiendas, se puntualizan obligaciones específicas que, de no seguirlas, contravienen y afectan los principios de representación, equidad durante la contienda, neutralidad, pluralidad, libertad de voto y democracia. Dichas normas exponen que, candidatos a presidentes municipales, partidos o coaliciones y funcionarios públicos (actores políticos para este análisis, quedando excluidos del ejercicio dentro de la contienda electoral toda organización de orden privado) tienen las siguientes obligaciones: Según los artículos 186, 187, 189 y 217 del Código de Instituciones y Procesos Electorales del Estado de Puebla, que definen el inicio del proceso electoral dentro de estos procesos, así como las fechas de precampaña y campaña, los actores políticos deberán mantenerse al margen de actuación respecto a las fechas por ley, indicadas.

De acuerdo a lo señalado en el artículo 200 Bis del mismo Código, los actores políticos deberán abstenerse de realizar actos de campaña, difundir propaganda electoral, realizar actos de proselitismo o promoción de su imagen personal expresando su postulación a un cargo público y dirigidos a la ciudadanía en general fuera de las fechas indicadas por ley; en el mismo sentido, los partidos durante o después de su procedimiento interno de selección respectivo, y previo al registro constitucional de candidatos deberán mantener restringida la imagen de partido o imagen del candidato sobre los votantes.

Conforme a los artículos 49, fracción VII del Código de Instituciones y Procesos electorales del Estado de Puebla y 200, inciso D, fracción I, actores políticos deberán mantener los techos financieros estipulados por ley, sin aceptar aportaciones o donativos en dinero 0 especie de personas o empresas mexicanas de carácter mercantil que rebasen dichos alcances. El artículo 45, párrafo primero, inciso a) del mismo Código, indica que las actividades de los partidos deberán efectuarse ajustando, conduciendo y tomando 
responsabilidad de toda actividad y conducta, de dicho partido, coalición y candidato, bajo respeto y libre participación política de los demás partidos.

\section{Principios, límites y obligaciones de Rafael Moreno Valle como servidor público}

Para mayor comprensión del contexto en el que se presenta el objeto resulta primordial definir qué es un servidor público y de qué trata, un servidor público. De acuerdo al Compendio de Legislación Nacional Electoral, tomo 2, en el apartado de la Ley General en Materia de Delitos Electorales, título primero, capítulo 1, artículo 5, define que un servidor público es:

"La persona que desempeñe un empleo, cargo o comisión de cualquier naturaleza en la Administración Pública Federal o local centralizada, organismos descentralizados federales o locales, empresas de participación estatal mayoritaria federales o locales, organizaciones y sociedades asimiladas a éstas, fideicomisos públicos federales o locales, en las legislaturas federal o locales y en la Asamblea Legislativa del Distrito Federal, en los poderes judiciales federal o locales o Tribunal Superior de Justicia del Distrito Federal, o que manejen recursos económicos federales o locales, así como en los organismos a los que la Constitución, las constituciones locales o el Estatuto de Gobierno del Distrito Federal otorguen Autonomía". (INE et al., 2016, tomo 2, p. 245)

Su marco normativo fundamental se encuentra en la Constitución Política de los Estados Unidos Mexicanos, en la Ley Federal de Responsabilidades de los Servidores Públicos, en la Ley Federal de Responsabilidad Patrimonial del Estado y en la Ley Federal de Responsabilidades administrativas de Servidores Públicos que, en conjunto, otorgan las reglas de comportamiento político, obligaciones, responsabilidades y sanciones de los servidores públicos. 
En términos de propaganda, el artículo 134 párrafo 8, de la Constitución Política de los Estados Unidos Mexicanos indica que "La propaganda, bajo cualquier modalidad de comunicación social, que difundan como tales, los poderes públicos, los órganos autónomos, las dependencias y entidades de la administración pública y cualquier otro ente de los tres órdenes de gobierno, deberá tener carácter institucional y fines informativos, educativos o de orientación social. En ningún caso esta propaganda incluirá nombres, imágenes, voces o símbolos que impliquen promoción personalizada de cualquier servidor público".

\section{Principios, límites y obligaciones de los partidos políticos}

De acuerdo al artículo 54, párrafo primero, inciso a) del Código de Instituciones y Procesos Electorales del Estado de Puebla, partidos y coaliciones nacionales atienden como entidades de interés público y con calidad de garante respecto a la conducta de sus militantes, dicho esto, la Coalición Compromiso por Puebla, integrada por los partidos políticos Partido Acción Nacional, Partido de la Revolución Democrática, Convergencia y Nueva Alianza, tiene la obligación de conducir sus actividades dentro los marcos legales, siguiendo los principios de representación y democracia bajo condiciones de equidad y respeto tanto en la libre participación política de los demás partidos como en los derechos de los ciudadanos.

\subsection{El medio de comunicación y los principios de libertad de expresión.}

La libertad de expresión, piedra angular de todo sistema democrático, conlleva dos dimensiones, por un lado, se vincula a la dignidad del ser humano pues en ésta impulsa a su participación dentro de la sociedad; por otro, se vincula al entorno participativo dentro del espacio público, el cual se construye a partir de la libertad (Pizaña y Pérez, 2016).

Expresado de otra forma, garantiza que la comunicación política se lleve con libertad pues permite que el tráfico de ideas se vinculen a los principios de legitimidad democrática y pluralismo político, siendo evidente y maximizado en el fomento del debate público, y en este 
sentido, al ser parte parte indispensable de la formación de la opinión pública, como público crítico masivo, se le reconoce como contrapeso del poder (Mendoza, 2011)

Los artículos 6 y 7ํㅡㄹ primer párrafo, de la CPEUM; 19, párrafos 2 y 3, del Pacto Internacional de Derechos Civiles y Políticos (PIDCP); y 13, párrafo 2, de la Convención Americana sobre Derechos Humanos (CADH), reconocen el derecho fundamental a la libertad de expresión; de hecho, dentro del contexto del debate político, que incluye propaganda electoral, este derecho se interpreta y maximiza. Además, como instrumento formativo en la opinión pública, induce condiciones para una elección informada, libre y auténtica. Sin embargo el derecho a la libertad de expresión tiene límites constitucional y legalmente que tratan el respeto a la moral, los derechos de terceros, la paz social y el orden público (tesis XII/2009). (Pizaña y Pérez, 2016).

En aras de mantener informada a la sociedad y debido al ejercicio crítico principalmente en procesos electorales, el periodismo es reconocido y su protección es garantizada internacionalmente como labor fundamental en el funcionamiento de las democracias, incluyendo su línea editorial así como la libre comercialización, siempre y cuando se conduzcan con veracidad y su finalidad sea fomentar el debate democrático.

El objetivo de regular estos actos radica en el respeto a los principios electorales, en el estudio de caso del presente, se trata de evitar que una opción política tome ventaja en relación con sus opositores por exponerse antes del tiempo previsto por la ley, difundiendo propaganda política en espacios de radio, televisión o en espacios publicitarios utilizando imagen o exponiendo propuestas. Todo servidor público, debe mantener una conducta imparcial con relación a la ciudadanía y conducirse con legalidad, honradez, lealtad, imparcialidad y eficiencia de acuerdo con la guía del buen actuar. En este orden de ideas y bajo la queja suscrita, Rafael Moreno Valle, siendo servidor público, debía regir su comportamiento bajo las responsabilidades y obligaciones que confieren a su cargo, además 
de mantenerse al margen de todo comentario que atente los principios de una contienda electoral.

Aunado a esto, la Coalición Compromiso por Puebla debería cerciorar que la conducta de sus militantes se conduzca siempre dentro de la legalidad y conforme a los principios del Estado democrático, esto, debido a que el servidor público en cuestión además de difundir su nombre e imagen, expresó abiertamente sus ambiciones presidenciales hacia las elecciones de 2018 en la entrevista presentada por la revista "Líderes Mexicanos".

De igual forma, la revista "Líderes Mexicanos" de acuerdo a su línea editorial, toma la responsabilidad de la conducción y reproducción de la entrevista a Rafael Moreno Valle, así como la decisión de colocar su imagen en la portada de la revista impresa y su página de internet bajo ejercicio de libertad de expresión, por ser figura de importancia pública y como gancho publicitario de la misma revista, razón por la cual la propaganda fue difundida en distintos medios de la República Mexicana.

\section{Afectaciones en la opinión pública desde la teoría de la espiral del silencio}

La postura de Elisabeth Noelle-Neumann en la teoría de la espiral del silencio es referencia en el presente estudio debido a que incluye el aspecto psicológico obviado en algunos estudios de la comunicación política. Esto permite un enlace más orgánico entre el cúmulo de significaciones en el discurso político, en la cultura política y el imaginario social construido en la realidad en la que se emite.

El postulado teórico de Noelle-Neumann conlleva símbolos que rigen el control social racional desde la socialización primaria, es decir, coincide con Berger y Luckman al afirmar que el individuo aprende en sus primeros años valores, actitudes, "buenos comportamientos" 
y las consecuencias de no llevarlos a cabo (2003); y cobran importancia en la comunidad cuando se expresan públicamente (Noelle-Neumann, 1993).

De acuerdo a sus hallazgos, el proceso de la opinión pública asegura la integración de grupos y sociedades, y por ende la supervivencia de las comunidades desde la capacidad de acción. Aquí, centra su interés en el miedo innato del ser humano al aislamiento como la clave que ayuda a comprender el fenómeno de la opinión pública a partir de cuatro postulados aplicados a un caso de estudio: "el individuo experimenta un constante miedo al aislamiento", a partir de este miedo, el hombre se motiva a ser aceptado, de alcanzar una posición, seguridad y protección; "la sociedad amenaza con aislamiento al individuo que se desvía", en consecuencia, el individuo evita enemistad; "Ios resultados de este cálculo afectan al comportamiento en público" partiendo de una baja autoestima en la que deciden expresar u ocultar la opinión; "el individuo intenta captar continuamente las corrientes de opinión" para mantenerse dentro de la comunidad (Noelle-Neumann, 1993; Noelle-Neumann en Dittus, 2005).

Por un lado, vincula el comportamiento individual a la opinión pública desde la aprobación o desaprobación de expresiones y conductas, observable en las redes sociales, donde al opinar se refuerza el anonimato sin sentir en consecuencia, el contrapeso del aislamiento (Noelle-Neumann en Mendoza, 2013); mientras que como control de la sociedad, nivela el consenso desde los valores y objetivos de la comunidad, por ende, adquiere poder ante el gobierno y ante los miembros de la sociedad (Noelle-Neumann, 1993).

Utiliza la teoría no sólo para explicar sino para comprender la forma en que la opinión pública como dominante, doblega a los individuos a comportarse bajo ciertas normas haciendo uso del miedo al aislamiento social y, en el caso de actores políticos, perdiendo el apoyo popular (Noelle-Neumann en Mendoza, 2013). En palabras de Norbert Lechner: "dado que las identidades colectivas siempre se apoyan en la diferenciación del Otro, estas diferencias suelen ser fijadas y percibidas más fácilmente como amenaza y agresión. Esto actualiza el 
miedo al conflicto y suscita un fuerte deseo de estabilidad" (Lechner, 2013). Por tanto, define la opinión pública como "opiniones y comportamientos en áreas cargadas de valores, que cada individuo puede expresar en público previendo una buena acogida. En otras palabras, las opiniones y modos de comportarse que pueden expresarse y exhibirse en público sin arriesgarse al aislamiento" (Noelle-Neumann, 2010), donde la valentía que expresan las personas cuando la toman de un medio predominante, o tienen ecos positivos es empoderada.

En esta teoría, los medios de comunicación de masas, como transmisores que crean o recrean la realidad social, son el medio principal desde donde el individuo observa su entorno, aquí los periodistas creadores de opinión, muestran tanto el panorama simbólico como las opiniones que conducen a la aprobación o al aislamiento, a lo que contrapone dos significados a la opinión pública, por un lado como crítica desde su discusión racional que aplaude o condena al gobierno, mientras que por otro lado, expresa conformismo (NoelleNeumann en Dittus, 2005). Aunque racionalmente la opinión pública se enfoca en la participación democrática en lo que respecta a temas públicos esperando que el Estado considere sus opiniones, existe la preocupación de que esta opinión pueda ser manipulada desde el Estado a través de los medios (Noelle-Neumann, 1993).

\section{Discusión}

\section{La cultura política y la realidad social}

Si la cultura política surge de "todo este conjunto de normas escritas y no escritas, convenciones, modas, hábitos y costumbres representan el repertorio discursivo perfecto capaz de alimentar las ideas de respeto, aprecio y aceptación" (Dittus, 2005) que implica el imaginario social, y éste es reflejo de la realidad social, en Puebla, durante la contienda electoral del 2010, se respiraba hartazgo tanto por el mal desempeño del partido hegemónico como por resentimiento del comportamiento político de gobernantes anteriores al verse 
inmersos en temas de corrupción. El triunfo de Rafael Moreno Valle en el estado de Puebla, fue una bocanada de aire fresco con expectativas que se sostenían firmemente en su constantemente expresado "compromiso" (Meyer, Castillo y Rios, 2013) electoral. Sin embargo, no pasó mucho en que inició las marcadas luchas con el INE al reincidir constantemente en la promoción de su imagen personal llegando a difundirla a nivel federal (Imagen Radio, 2017).

Mientras el país sufría de incremento en índices delictivos, el cuestionamiento respecto al retorno del PRI a la presidencia rondaba en la ciudadanía por el miedo a cierta lógica autoritaria (Ackerman en Hernández y Pansters, 2012). Mientras a nivel federal, la expectativa de eficiencia debido al desempeño en su gobierno estatal, puso a Enrique Peña Nieto en un papel cuya exigencia demandaba constantemente buenos resultados, el destape abrumador de un pre-candidato como Rafael Moreno Valle, cuya imagen personal se difundió en distintos rincones del país, dio pie a cuestionar su recurrente irregulado comportamiento por parte de la prensa, contrario al buen comportamiento (Noelle-Neumann, 2003) que debe regir a un servidor público.

\section{El papel de la opinión pública}

La primera alternancia en el estado de Puebla ha resultado un punto de partida para el análisis a profundidad de los esfuerzos mercadológicos durante la contienda. Sin embargo, los esfuerzos no paran en ese punto. La comunicación electoral se transforma en comunicación gubernamental al momento del triunfo, marcando pautas específicas tanto de comportamiento como de actuación, no sólo a nivel comunicativo sino regulado por instancias oficiales. En tanto que la comunicación electoral como primer puente de enlace entre la ciudadanía y el actor político, inunda al electorado de mensajes persuasivos (Mazzoleni, 2010), la comunicación gubernamental busca expresar el servicio y papel desempeñado por el servidor público centrado en sus resultados (Canel y Sanders, 2011). 
Un análisis realizado por Meyer, Castillo y Ríos respecto a su primer año de labores como gobernador, muestra que su discurso simbólico enfocado al compromiso (2013) y la creación de lazos, para conectar con la ciudadanía (Habermas, 1992), le dio el triunfo. Sus fuertes rasgos personales y su herencia histórica le dieron peso como líder político, creando un personaje de alta estima. Sin embargo, al entrar en funciones se inclinó por dedicarse a alcanzar su aspiración a la candidatura presidencial de 2018 (Meyer, Castillo y Ríos, 2013), llegando a considerarse como una "sociedad policéntrica de grandes organizaciones" (Habermas en Dijkman, 2012), donde se llegó incluso a concluir que con las nuevas relaciones adquiridas a nivel federal, tomó impulso para iniciar su proyecto de difusión nacional (Meyer, Castillo y Ríos, 2013).

Dejar de lado la participación ciudadana, alianzas políticas y empresarios, mermó el debate abierto y crítico (Habermas en Dijkman, 2012) desde el primer año de gobierno, causando conflictos no sólo en los medios que mostraban cada vez más desinterés en sus informes de comunicación, sino en la opinión pública al saberse desplazada (Meyer, Castillo y Ríos, 2013), sin dar pie a un consenso centrado en valores y objetivos de la comunidad (NoelleNeumann, 1993).

Debido a esto, regionalmente su reputación tendía a decrecer al no resultar congruentes los resultados presentados contra las necesidades reales de la ciudadanía. Mientras la inseguridad aumentaba, buena parte del presupuesto era direccionado a grandes obras de infraestructura y a la difusión y propaganda de dichas obras no sólo a nivel estatal y federal, dejando entrever la eficiencia de su desempeño. Manipulación como instrumento de poder que podría definirse como un posible alejamiento de la democracia (Habermas en Morales y Gómez et al., 2011; Sopena, 2008). El manejo de su imagen personal, apoyado por sus rasgos de personalidad y carisma, fueron controversiales por su recurrente declaración de la búsqueda de la silla presidencial rumbo a las elecciones del 2018, dejando abierta la crítica de la prensa, quien más que relaciones públicas, fungieron como catalizadores de control 
público, haciendo eco en la masa (Habermas en Cuadra, 2006), interpretando y recreando el panorama simbólico (Noelle en Dittus, 2005)

Dicho sea de paso, debido al replicar de notas por parte de la prensa causada por las constantes infracciones durante los 6 años de su gobierno, es posible que a nivel nacional, se haya aportado en mayor medida a la percepción negativa de su imagen, aunque bien eso podría ser estudiado con mayor profundidad más adelante.

Si la opinión pública es un proceso de integración del que dependen los gobernantes, donde su reputación es regulada no sólo por normas formales, sino por la opinión (NoelleNeumann, 1993), a Moreno Valle le resultó contraproducente. Esto es, mientras se le ve exponiendo su estado de resultados, enalteciendo y difundiendo la imagen de un gobierno eficiente, por otro realzaba su poco apego a las normas. El slogan "Rafael Moreno Valle, el nuevo presidenciable" utilizado por la revista "Líderes Mexicanos" bajo argumento de libertad de expresión y promoción editorial, puso bajo reflectores a un servidor público que por un lado exponía eficiencia y apertura en participación ciudadana, mientras que por otro, puso en duda no sólo su calidad moral y comportamiento. Aunado a esto surgieron interrogantes respecto a grandes montos del presupuesto estatal direccionados a su promoción personal, razón por la cual nació la queja del presente estudio de caso.

Aunque durante la resolución se muestra una orden que indicó remover de forma inmediata todas las publicaciones impresas y colocadas en la web, la queja en contra de los actores políticos señalados no procedió. Bajo la postura desarrollada en este apartado en conjunto con la teoría con que se ha analizado, considero que el PES debió haber analizado y ejercido con mayor fuerza su función debido a los antecedentes de violaciones previas que presentó el servidor público.

\section{Conclusiones}


Rafael Moreno Valle actuó en contra de convenciones y regulaciones asentadas en la legislación electoral, el órgano regulador, INE, le sanciona pues rebasa constantemente los límites de comportamiento establecidos por ley, no sólo del buen actuar, sino respecto a lo que como servidor público le compete, alejándolo del concepto de democracia que define el modelo habermasiano.

Si bien la revista "Líderes Mexicanos" argumenta el uso de la libertad de expresión, además de difusión de propaganda por decisión editorial. El estudio de caso no es el único en el que, en conjunto con el entonces gobernador, difunde propaganda considerada electoral bajo título editorial. El punto de inflexión radica en determinar hasta qué punto la revista es altavoz de opinión o partidaria política (Casas en Dittus, 2005) incidiendo directamente en la permanencia de los votantes con anticipación. Sumado a esto, si el gobierno estatal fomentó comercialización de su persona a través de la editorial de la revista, al confirmar bajo esta acción no necesitar la aprobación de la opinión pública, además de los puntos expuestos, se confirma que $\mathbf{H} 2$ existen discursos de servidores públicos que resultan propaganda electoral.

El apartado metodológico que corresponde al análisis del mensaje con uso del análisis crítico del discurso y análisis de contenido como herramienta, se encuentran en proceso de operacionalización, sin embargo, tomar este primer caso para clasificar adecuadamente la dimensión del discurso ha servido para a partir de los hallazgos encontrados hasta ahora, tomar la decisión de ampliar el corpus y verificar la dirección sintáctica, retórica, así como tendencias de comportamiento desde el discurso político durante su periodo de gobierno, bajo condición de ser mensajes declarados por el servidor público y que hayan incurrido en alguna queja, como la presente. De tal forma que este proceso, posterior a su validación, podrá aportar a réplicas como modelo de análisis cualitativo del discurso político durante periodos de gobernabilidad.

Debido a esto, se presenta este estudio como una herramienta para el fortalecimiento de análisis del PES, con la finalidad de ejercer con argumentos más sólidos las regulaciones. 


\section{Bibliografía}

Aceves, Francisco de J. (2009). Elecciones, medios y publicidad política en América latina: los claroscuros de su regulación. Comunicación y Sociedad. (12), 33-62.

Acosta, Miguel. (2013). Cap. Análisis de contenido: propuesta metodológica y un ejemplo de su aplicación en el análisis de la cobertura electoral de noticieros de televisión en México. En Metodología de investigación en ciencias sociales. Aplicaciones prácticas. En buen plan. 243-281

Ahuactzin, Carlos E.; Meyer Rodríguez, José A. (2017). Publicidad electoral televisiva y persuasión en Puebla 2010. Una aproximación desde el Análisis Crítico del Discurso. Comunicación y Sociedad, (29),41-68. https://www.redalyc.org/articulo.oa?id=346/34650597004

Betancourt, Felipe. (2014). La importancia del debate público para la democracia. IEEM. Estado de México.

Berger, P., Luckmann, T. (2003). La construcción social de la realidad. Buenos Aires: Amorrortu Editores.

Castells, Manuel. (2008). The new plublic sphere: global civil society, communication networks, and global governance. ANNALS, AAPSS, 616, 78-903

Cea D’Ancona, M. A. (1996) Metodología cuantitativa: estrategias y técnicas de investigación social. España. Síntesis.

Cegarra, José (2012). Fundamentos teórico epistemológicos de los imaginarios sociales. En Cinta moebio. Venezuela. 43, 1-13

Constantinescu, S. A. (2012). Public sphere and New media. Case study. Wikileaks. Journal of Media Research. ubb media centre. 3(14), 95-109

Díaz Jiménez, Oniel F. (2015). Marketing político y profesionalización de las campañas electorales presidenciales del Partido Acción Nacional y del Partido de la Revolución Democrática, 1994-2006. Polis. Vol 11(1), 119.168

Dijkman, Léon. (2012). Do you want to know a secret?. Amsterdam Law Forum. 49-64

Dittus, Rubén. (2005). La opinión pública y los imaginarios sociales: hacia una redefinición de la espiral del silencio. Athenea Digital, (7), 61-76

Echeverría Victoria, Martín. (2018). Comercialismo periodístico y cobertura estratégica de las elecciones. Modelo teórico metodológico para explorar su relación. Estudios sobre el Mensaje político 24 (1), 155-172 
Espinosa, Santiago; Figueras, Victor M.; Miranda, Martha. (2019). Dimensiones $y$ consecuenvias de la reelección consecutiva. Año XVIII (60), 39-62

Fraser, Nancy. (1999). Repensando la esfera pública: Una contribución a la crítica de la democracia actualmente existente. Ecuador Debate. 46, 139-174

González, Pablo. (1981). La cultura política en México. Nexos (39). https://www.nexos.com.mx/?p=3914

Gutiérrez, Silvia. (2006). Discurso político y argumentación. UAM. https://www.researchgate.net/publication/251886295

Habermas, Jürgen. (1992 en inglés) [2010], Facticidad y validez. Sobre el Derecho y el Estado democrático de derecho en términos de teoría del discurso, Madrid, Trotta. (Capítulo 7).

Hernández, Roberto; Fernández-Collado, Carlos; Baptista, Pilar (2006). Metodología de la investigación. McGraw-Hill. México.

Hernández, Rogelio; Pansters, Wil G. (2012). La democracia en México y el retorno del PRI. Foro internacional. V. 52, 4(210), 755-795

Imagen Radio. (2017). Moreno Valle aspira a la presidencia nacional del PAN / Primera Emisión.

https://www.youtube.com/watch?time_continue=34\&v=76LQnS4M2Bg\&feature=emb_lo g

INE, FEPADE, UNAM, TEPJF. (2016) Tomo 1. Constitución política de los Estados Unidos Mexicanos. Compendio de Legislación Nacional Electoral. México

INE, FEPADE, UNAM, TEPJF. (2016) Tomo 2. Ley General de Instituciones y Procedimientos Electorales. Ley del Sistema de Medios de Impugnación en Materia Electoral. Ley General en Materia de Delitos Electorales. Ley General de partidos Políticos. Ley Federal de Consulta Popular. Compendio de Legislación Nacional Electoral. México

Lechner, Norbert. (2013). Cultura política y gobernabilidad democrática. Temas de la democracia. Conferencias magistrales 1. Instituto Federal Electoral. México. https://biblio.juridicas.unam.mx/bjv/detalle-libro/3921-cultura-politica-y-gobernabilidaddemocratica-coleccion-temas-de-la-democracia-conferencias-magistrales-1

López, A., Chihu, Aquiles. (2011). Símbolos, lenguaje y espectáculo en la democracia: el escepticismo político de Murray Edelman. Espiral, 18(50), 101-139.

Mazzoleni, Gianpietro. (2010). La comunicación política. Madrid. Alianza Editorial.

Mendoza, Leticia. (2011). Perspectivas teóricas sobre la opinión pública: Habermas y NoelleNeumann. Toda gente. 
Meyer, José Antonio; Castillo, Jorge Luis; Ríos, Carla Irene. (2013). Comunicación política y opinión pública: el caso del primer gobierno de alternancia política en Puebla. Global Media Journal México. Vol 10 (19), 69-84

Morales y Gómez, Juan Miguel; Rodríguez Manzanares, Eduardo; Reyes Montes, Ma. Cristina: O'quinn Parrales, José Antonio. (2011). Opinión pública y democracia, algunas aportaciones para su estudio. Espacios públicos

Neuendorf, Kimberly A. (2017). The Content Analysis Guidebook. Cleveland. SAGE.

Newman B. (1999). Handbook of Political Marketing. SAGE Publications.

Noelle-Neumann, Elisabeth. (1993). La espiral del silencio. La opinión pública y los efectos de los efectos de los medios de comunicación. Comunicación y Sociedad. Vol. VI (1 y 2). 9-28. https://hdl.handle.net/10171/8031

Noelle-Neumann, Elisabeth. (2010). Turbulencias en el clima de opinión: aplicaciones metodológicas de la teoría de la Espiral del Silencio. CIC, vol. (15) 301-318

Peschard, J. (2000). Comportamiento electoral. En L. Baca Olamendi et al. (Compiladores), Léxico de la Política. 68-75

Pizaña, M., y Pérez Parra, J. A. (2019). Libertad de expresión y protección al periodismo dentro del procedimiento especial sancionador. Cuadernos de Divulgación de la Justicia Electoral 35. Colección TEPJF

Pintos, Juan L. (1995). Orden social e imaginarios sociales. En propuesta de investigación. Universidad de Santiago de Compostela. 101-127

Quintanilla, Víctor H. (1993). Memoria e imaginario social: de la oralidad a la escritura. Universidad Mayor de San Andrés, Bolivia.

Reynoso, Víctor. (2008). Puebla: una década de legislación electoral. En J. Peschard, El Federalismo Electoral en México. México D.F: Cámara de Diputados. 547-58

Sánchez, Lucía A.; Meixueiro, Gustavo; Contreras, Nayelli. (2018). Propaganda política en México y Estados Unidos: aproximaciones teórico-metodológicas discordantes.

Secretaría de la Función Pública. Consultado en junio del 2020. https://imt.mx/images/files/SPC/Curso\%20Nociones/contenidos/modulo6/mod_6_2.htm

Steel, R. (2003). Prólogo. En La opinión pública. España. Cuadernos de Langre.

Sopena Palomar, Jordi. (2008). El fenómeno de la opinión pública: líneas de investigación en Europa. Barcelona. RUTA (01)

SPF. Módulo 6. Responsabilidades de los servidores públicos y código de ética. Tema 1. Marco jurídico de los servidores públicos. En Nociones básicas de la administración 
pública

federal.

https://imt.mx/images/files/SPC/Curso\%20Nociones/contenidos/modulo6/mod_6_2.htm

Valdés, Leonardo. (2000). L. Baca Olamendi et al. (Compiladores). Léxico de la Política, 199206

Valdés, Leonardo. (2019). Cien años del sistema electoral mexicano (1917-2017). mimeo

van Dijk, T. A. (2004). Discurso y dominación. Grandes conferencias en la Facultad de Ciencias Humanas, 27(4), 225-248. https://doi.org/10.3406/cehm.2004.1622

Videoteca Jurídica Virtual (19 de octubre de 2015). Mesa 1. Modelo de comunicación político electoral y el régimen sancionador, en el Observatorio Judicial Electoral sobre el modelo de comunicación política. Perspectivas y retos del procedimiento sancionador electoral y la libertad de expresión en materia política. Recuperado de: https://www.juridicas.unam.mx/videoteca/evento/observatorio-judicial-electoral-sobre-elmodelo-de-comunicacion-politica-perspectivas-y-retos-del-procedimiento-sancionadorelectoral-y-la-libertad-de-expresion-en-materia-politica/2015-10-19/6124-mesa-1modelo-de-comunicacion-politico-electoral-y-el-regimen-sancionador

Yanes Mesa, Rafael. (2006). La entrevista como género de la comunicación política. Chasqui 96, 52-55 http://hdl.handle.net/10469/13510

ANEXO 1. Operacionalización para la aplicación de análisis de contenido de la entrevista del servidor público en versión estenográfica.

\begin{tabular}{|c|c|c|c|c|}
\hline & & & $\begin{array}{l}\text { JCCIÓN } \\
\text { os }\end{array}$ & LIBRO \\
\hline \multirow{4}{*}{$\begin{array}{l}\text { Discurso } \\
\text { Construcción } \\
\text { de carácter } \\
\text { persuasivo que } \\
\text { permite } \\
\text { comunicar } \\
\text { ideas } \\
\text { propuestas, y } \\
\text { referidas a } \\
\text { objetos }\end{array}$} & \multirow{4}{*}{$\begin{array}{l}\text { Comunicación } \\
\text { Gubernamental: } \\
\text { "'se refiere a los } \\
\text { objetivos, el papel y la } \\
\text { práctica de la } \\
\text { comunicación } \\
\text { implementada por los } \\
\text { políticos ejecutivos y } \\
\text { funcionarios de } \\
\text { instituciones públicas }\end{array}$} & \multirow{4}{*}{$\begin{array}{l}\text { Identidad. } \\
\text { lo que una organización } \\
\text { presenta de sí misma en } \\
\text { términos } \\
\text { comportamiento, de } \\
\text { comunicación } \\
\text { simbolismo, así como } \\
\text { aspectos visuales y no } \\
\text { materiales de la }\end{array}$} & \multirow{3}{*}{$\begin{array}{lr}\text { 1. Respecto a obra } \\
\text { pública, desarrollo } \\
\text { turístico } & \\
\text { agropecuario, } & \\
\text { inversión, obras de } \\
\text { infraestructura } & \text { de } \\
\text { hospitales, salud } & 0 \\
\text { educación. } & \\
& \\
\end{array}$} & \\
\hline & & & & \begin{tabular}{|l} 
b. Se menciona a \\
grosso modo
\end{tabular} \\
\hline & & & & c. No s \\
\hline & & & 2. Se utilizan adjetivos & \\
\hline
\end{tabular}




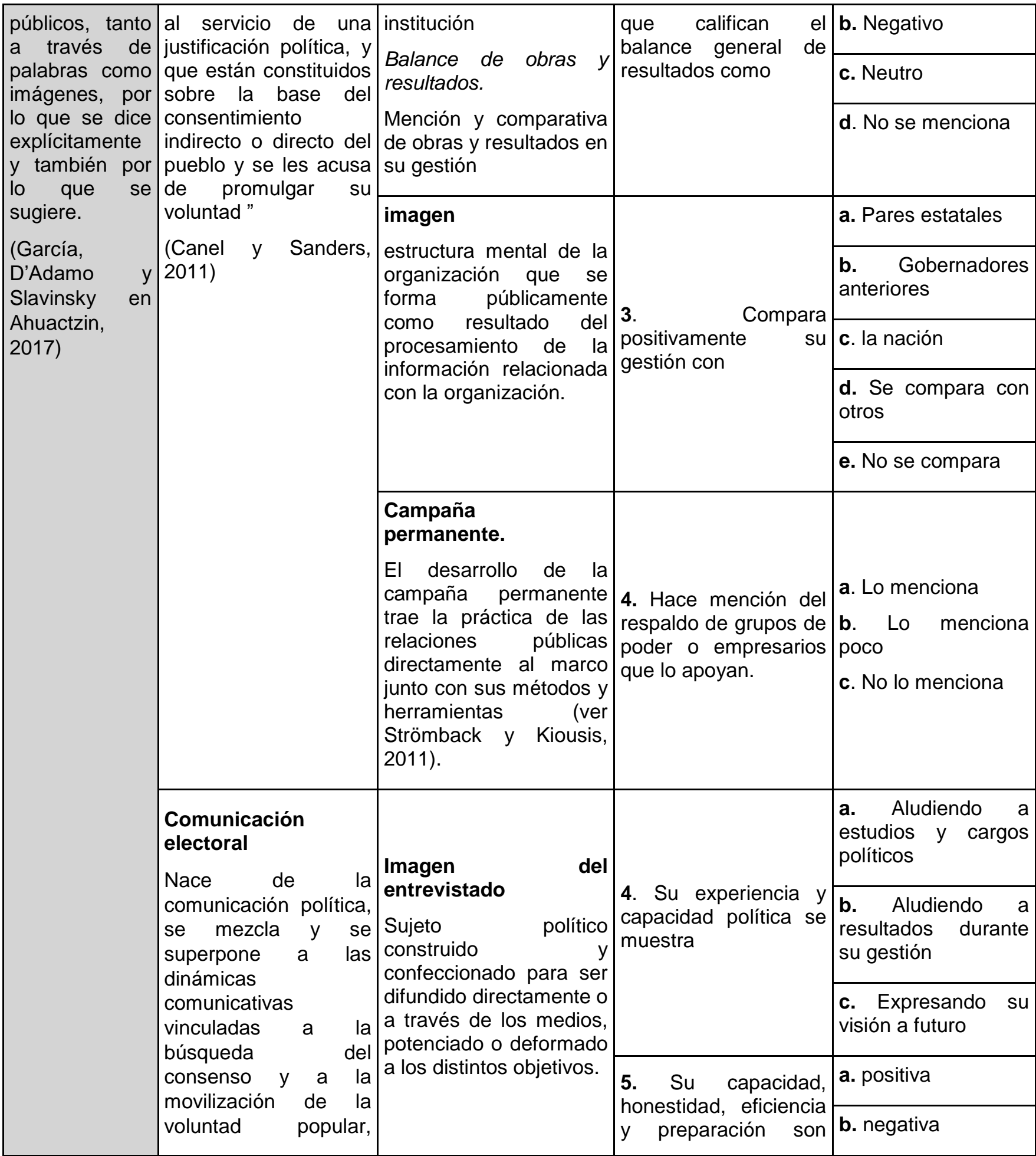

Facultad de Ciencias Sociales y de la Comunicación

Universidad de La Laguna

Avenida César Manrique, s/n; Campus de Guajara

38071 La Laguna, Tenerife (Islas Canarias - España) 


\begin{tabular}{|c|c|c|c|}
\hline \multirow{6}{*}{$\begin{array}{l}\text { cosas que tienen lugar } \\
\text { sobre todo en las citas } \\
\text { electorales. } \\
\text {-Mensaje persuasivo, } \\
\text { propaganda- } \\
\text { (Mazzoleni, 2010) }\end{array}$} & & \multirow{2}{*}{$\begin{array}{l}\text { mencionados de } \\
\text { manera }\end{array}$} & c. neutra \\
\hline & & & d. No se menciona \\
\hline & \multirow{2}{*}{$\begin{array}{l}\text { Ideales. } \\
\text { Principios y valores en } \\
\text { pro del bienestar de los } \\
\text { ciudadanos. }\end{array}$} & \multirow{2}{*}{\begin{tabular}{|lr} 
6. La aplicación de & de \\
buenas prácticas en \\
beneficio a & los \\
ciudadanos & es \\
mencionado &
\end{tabular}} & a. Si \\
\hline & & & b. No \\
\hline & \multirow{2}{*}{$\begin{array}{l}\text { Propaganda } \\
\text { Visión ideal de la } \\
\text { democracia. } \\
\text { Mensaje seductivo que } \\
\text { favorece la elección de } \\
\text { los candidatos más } \\
\text { dotados de fantasía. }\end{array}$} & \multirow[b]{2}{*}{$\begin{array}{l}\text { 8. Se menciona un } \\
\text { estado utópico del } \\
\text { Estado de Puebla. }\end{array}$} & a. $\mathrm{Si}$ \\
\hline & & & b. No \\
\hline
\end{tabular}

\section{Forma de citar este artículo en bibliografías}

HERMIDA, R.M. (2017): "Actos anticipados de campaña presidencial y efectos en la opinión pública: El caso de Rafael Moreno Valle en Puebla”, en Revista PANGEA № 8, páginas 49 a 84. Tenerife: Red Académica Iberoamericana de Comunicación. Recuperado el _ de de 2 de: http://www.revistapangea.org 